- Laboratorium: журнал социальных исследований. 2020. 12(3):212-215

DOI: $10.25285 / 2078-1938-2020-12-3-212-215$

\title{
Михаил Наконечный
}

\section{Golfo Alexopoulos. Illness and Inhumanity in Stalin's Gulag. New Haven, CT: Yale University Press, 2017. 328 pp. ISBN 978-0-300-17941-5.}

\begin{abstract}
Михаил Наконечный, Aleksanteri Institute, University of Helsinki. Aдрес для переписки: University of Helsinki, Unioninkatu 33, Helsinki, 00014, Finland. mikhail.nakonechnyi@helsinki.fi.
\end{abstract}

В 2017 году в издательстве Йельского университета вышла монография американской исследовательницы Гольфо Алексопулос «Illness and Inhumanity in Stalin's Gulag». Эта публикация по праву может считаться важной вехой в историографии ГУЛАГа - гигантской системы эксплуатации принудительного труда в СССР 19301960 годов. Алексопулос первой за много лет вернулась к ключевым вопросам истории сталинских лагерей, а именно к уточнению числа погибших заключенных и природе институционального насилия самой лагерной системы.

Работу Алексопулос невозможно адекватно оценить без учета сложного политизированного историографического контекста проблемы. До открытия архивов в 1989-1991 годах в западной литературе количество жертв в ГУЛАГе оценивалось десятками миллионов. Саму систему образно называли «0свенцимом без печей», где заключенных намеренно уничтожали трудом. Выйти на свободу живым было практически невозможно, и количество освобождений было якобы минимальным (Conquest 1990). 0днако, согласно рассекреченным данным центрального аппарата ГУЛАГа, опубликованным в начале 1990-х после распада СССР, из 18 млн человек, прошедших через систему, погибло «только» 1,7 млн, 90\% заключенных пережили свое заключение и освободились (Безбородов и Хрусталев 2004; Getty, Rittersporn, and Zemskov 1993). Лишь относительно недавно несколько исследователей (Бердинских 2001; Исупов 2000; Applebaum 2004; Ellman 2002; Khlevniuk 2004) обратили внимание на так называемую «актировку» (досрочное освобождение заключенных по инвалидности) как потенциально значимый фактор в анализе ведомственной статистики освобождений. Согласно мемуарам бывших заключенных, «актирование» позволяло лагерной администрации искусственно снижать коэффициенты смертности в отчетах (Левенштейн 2001). Книга Алексопулос - попытка проанализировать взаимосвязь между «актировкой», освобождением и смертностью более детально.

В самом широком смысле монография впервые рассматривает функционирование ведомственной медицины ГУЛАГа во взаимосвязи с экстремальной эксплуатацией заключенных в лагерной экономике. Центральный аргумент и концепцию Алексопулос можно выразить следующим образом. Конечная цель ГУЛАГа как института заключалась не в уничтожении заключенных, а в их тотальной, убийственной и до сих пор недостаточно отрефлексированной эксплуатации. Эта эксплуатация интенсифицировалось по экспоненте и достигла пика в послевоенный период существования ГУЛАГа (1945-1953 годы), когда миллионы «доходяг» были якобы освобождены, но фактически просто отправлены умирать за пределы лагерей, 
скрыв тем самым миллионы смертей. Важно отметить, что, по Алексопулос, смертность в ГУЛАГе вызывалась не только экзогенными и эндогенными субъективными факторами (голодом, войной, климатом, произволом отдельных лагерных начальников), а именно структурными, имманентными чертами самой системы. Автор постоянно подчеркивает своеобразность и даже уникальность многих элементов в организации ГУЛАГа как системы исполнения наказания особого типа (питание, медицина, отношение к эксплуатации инвалидов и больных и т. д.).

По Алексопулос, медицина в ГУЛАГе полностью подчинялась производственным интересам лагеря (выполнению планов). Предельная эксплуатация тяжелобольных неизбежно вела к гибели значительного количества людей и появлению огромного числа инвалидов с разрушенным здоровьем. Содержать в лагерях их было невыгодно - инвалиды «ухудшали» статистику своими смертями и провоцировали непроизводительные расходы скудных ресурсов. Алексопулос показывает, как лагерные медики на местах оказывались между молотом и наковальней. С одной стороны, Москва требовала под угрозой репрессий снижать смертность заключенных и количество инвалидов (при этом не выделяя достаточных ресурсов), с другой стороны, обязывала обеспечивать максимальный вывод рабочей силы на производство, включая безногих и дистрофиков. Без фальсификации статистики выполнить эти абсолютно нереалистичные указания центральных властей было невозможно. Сотрудники ГУЛАГа прибегали к разнообразным ухищрениям для получения «правильных цифр». Таким образом, система представляла собой своеобразную «пирамиду эксплуатации». На вершине этой пирамиды находились приоритетные лагеря, получавшие самых здоровых заключенных. По мере ослабевания организма истощенных узников перевозили из «важных лагерей» в менее приоритетные колонии, и наконец, «выбрасывали» умирающих за пределы зон посредством «актировок», чтобы они своей смертью не портили отчеты, поступающие с периферии в центр.

Монография Алексопулос сразу в нескольких аспектах вносит значительный вклад в изучение советской тюремной системы. Во-первых, в книге постулируется принципиально новая, хотя и небесспорная, оценка смертности в 6 млн человек. Она складывается из официально зарегистрированной цифры в 1,7 млн смертей и более 4 млн умерших вскоре после освобождения. Во-вторых, несколько глав посвящены исследованию лагерной медицины и инвалидности. Эти темы до сих пор не получили должного освещения в литературе. Особо стоит отметить скрупулезный анализ нескольких редакций так называемого «Листа болезней» - сверхсекретной инструкции для присвоения формального статуса инвалида в лагерях. По Алексопулос, только терминальные стадии недуга (дистрофия третьей степени, туберкулез с распадом легких и др.) служили основанием досрочного освобождения. В-третьих, автор совершенно справедливо заостряет внимание на исполинском масштабе внутренних перебросок заключенных из лагеря в лагерь. Алексопулос убедительно доказывает, что перемещение сотен тысяч человек внутри системы зачастую определялось и мотивировалось состоянием здоровья лагерников (а не исключительно их «социальной опасностью» с точки зрения режима, как предполагалось ранее). Главным открытием здесь является прежде неизвестная 
функция исправительно-трудовых колоний (ИТК) как пункта концентрации истощенных и умирающих заключенных, потерявших трудоспособность в более приоритетных лагерях (Норильлаг, Воркутлаг). Ученые давно обращали внимание на более высокую смертность в ИТК в годы войны по сравнению с исправительнотрудовыми лагерями (ИТЛ) - Алексопулос обосновала и объяснила эти цифры. В целом, концептуализация ГУЛАГа как сложно устроенной иерархии более или менее приоритетных локаций именно с точки зрения состояния здоровья содержащихся там заключенных является новаторской. Она может помочь другим исследователям более корректно интерпретировать лукавые официальные показатели заболеваемости и смертности. Наконец, самое значительное достижение монографии - глава 6, посвященная «актировке» как методу манипуляции и занижению цифр смертности.

Несмотря на отмеченные сильные стороны книги, несколько тезисов и обоснованность подкрепляющих их аргументов вызывают вопросы. Прежде всего, цифра в 6 млн смертей и методология ее получения непрозрачны. Оценка основана на слишком широких экстраполяциях и допущениях. Алексопулос предполагает, что истощенных «доходяг» переводили «в иные места заключения» - в основном спецпоселки. Однако спецпоселения никогда ни формально, ни неформально не считались «местам заключения». В постоянно меняющейся структуре сталинской пенитенциарной системы под аббревиатурой «М3» понимались четко определенные типы мест лишения свободы - тюрьмы и колонии. Более того, Алексопулос цитирует сводные отчеты о движении заключенных «в другие места заключения» в качестве доказательства циклопического масштаба досрочного освобождения по инвалидности и экспоненциального роста освобождений инвалидов из системы в конце 1940-х и начале 1950-х годов. Однако эти сводки содержат сведения не об освобождении, а о переводе заключенных внутри системы (из лагеря в лагерь). Поэтому серьезные сомнения вызывает аргумент Алексопулос о послевоенном ГУЛАГе (1945-1953 годы) как самом жестоком и смертоносном периоде в его истории.

Данные интерпретации объясняются некоторой узостью источниковой базы «Illness and Inhumanity...». Автор работала в основном с материалами центрального аппарата ГУЛАГа в одном архиве (фонд Р-9414 в Государственном архиве Российской Федерации). Документация из местных архивов лагерных управлений практически не привлекалась. Поэтому из книги сложно получить представление о реальном воплощении директив об «актировании» на местах. Вывод о том, что инвалиды гибли сразу после освобождения, логичен, но опирается, по большей части, на косвенные, а не прямые доказательства. Например, массовых данных о смерти бывших заключенных в монографии нет, как и доказательств недоучета в центральной статистике для конкретных лагерей и хронологических отрезков. Также отсутствует и детальная информации о том, что же происходило с инвалидами после освобождения. Инвалиды а priori объявляются смертельно больными, хотя, возможно, кто-то из них и выжил. Более того, общего количества освобожденных инвалидов в 1930-1953 годах, в период «классического» ГУЛАГа, автор так и не приводит. Наконец, «актировка» осуществлялась не только структурами 
ГУЛАГа, но также органами лагерной Прокуратуры и Министерства Юстиции. Однако автор, к сожалению, почти не использовал материалы этих ведомств. Данный нюанс предопределил несколько смещенную бюрократическую оптику в повествовании, с преобладанием перспективы ОГПУ-НКВД-МВД. В результате сложный клубок институциональных противоречий между государственными акторами остался за пределами внимания Алексопулос.

Подводя итоги, отметим, что работа Алексопулос является первой попыткой за много лет критически переосмыслить центральную статистику смертей и освобождений, опубликованную в начале 1990-х Виктором Земсковым с соавторами (Getty, Rittersporn, and Zemskov 1993). Можно соглашаться или не соглашаться с основным аргументом Алексопулос об «уничтожающем» насилии системы лагерей, но весомость ее вклада в проблематику смертности в ГУЛАГе не подлежит сомнению. Любое исследование в идеале должно способствовать конструктивной дискуссии. Книга Алексопулос однозначно послужит катализатором для нового витка обсуждений важнейшего вопроса, которые многие историки считали решенным в начале 1990-х годов. Автор совершенно правильно подвергла сомнению цифру в 90\% выживших из сводной статистики ГУЛАГа. До сих пор эти данные некритически ретранслируется в десятках монографий и диссертаций в России и за рубежом как доказательства более «мягкой» природы сталинских лагерей. Лишь за это «Illness and Inhumanity...» заслуживает самой высокой оценки, несмотря на высказанные замечания.

\section{СПИСОК ЛИТЕРАТУРЫ}

Безбородов, Александр и Владимир Хрусталев, ред. 2004. Население Гулага: численность и условия содержания. Т. 4 в История сталинского Гулага. Конец 1920-х - первая половина 1950-х годов: собрание документов в $7 \mathrm{~m}$. М.: РОССПЭН.

Бердинских, Виктор. 2001. История одного лагеря (Вятлаг). М.: Аграф.

Исупов, Владимир. 2000. Демографические катастрофы и кризисы в России в первой половине ХХ века. Новосибирск: Сибирский Хронограф.

Левенштейн, Виктор. 2001. Повесть о моем отце. М.: Аргументы и факты.

Applebaum, Anne. 2004. Gulag: A History. New York: Anchor Books.

Conquest, Robert. 1990. The Great Terror: A Reassessment. New York: 0xford University Press.

Ellman, Michael. 2002. "Soviet Repression Statistics: Some Comments." Europe-Asia Studies 54(7):1151-1172.

Getty, J. Arch, Gábor T. Rittersporn, and Viktor N. Zemskov. 1993. “Victims of the Soviet Penal System in the Pre-War Years: A First Approach on the Basis of Archival Evidence." American Historical Review 98(4):1017-1049.

Khlevniuk, Oleg V. 2004. The History of the Gulag: From Collectivization to the Great Terror. New Haven, CT: Yale University Press. 